\title{
Indolent zygomycosis associated with deferoxamine chelation therapy
}

\section{Schmerzfreie Zygomykose bei Deferoxamin-Chelattherapie}

\author{
G. P. Prokopowicz, Suzanne F. Bradley and Carol A. Kauffman
}

Key words. Rhizopus, zygomycosis, deferoxamine.

Schlüsselwörter. Rhizopus, Zygomykose, Deferoxamin.

Summary. This paper describes a 71 -year-old man with myelodysplasia who required multiple transfusions and subsequent deferoxamine chelation therapy and who then developed indolent cutaneous and probable pulmonary infection with Rhizopus species. The patient did not have rapidly progressive infection as has been described in almost all previously reported deferoxaminetreated patients with zygomycosis. Amphotericin B therapy was successful in curing the infection.

Zusammenfassung. Es wird der Fall eines 71-jährigen Mannes mit Myelodysplasie beschrieben, der mehrfach Transfusionen mit anschließender Deferoxamin-Chelat-Therapie erhalten hatte und darauf einen schmerzlosen Hautprozeß 3 und wahrscheinlich auch eine Lungeninfektion durch Rhizopus spec. entwickelte. Im Gegensatz zu den bisher bei fast allen Patienten mit Zygomykose nach Deferoxamin-Behandlung beschriebenen Fällen entwickelte sich die Infektion im vorliegenden Fall langsam. Unter Amphotericin B-Therapie heilte die Infektion ab.

\section{Introduction}

Zygomycosis is an opportunistic fungal infection usually characterized by rapid progression of tissue invasion in patients with haematologic malignancies who have neutropenia and in patients with diabetes mellitus who have ketoacidosis [1, 2]. Recently zygomycosis has been noted in association with therapy with deferoxamine [3-12]. These patients have almost always been on haemodialysis and receiving deferoxamine for iron or aluminium excess states or have had haematologic conditions requiring repeated transfusions with subsequent iron overload treated with deferoxamine chelation. In patients on deferoxamine, as well as those with neutropenia and diabetic ketoacidosis, zygomycosis is almost always rapidly progressive and is usually fatal. We describe a patient who was receiving deferoxamine for myelodysplastic syndrome and who developed indolent zygomycosis manifested by necrotic skin lesions and a right upper lobe pulmonary infiltrate. His infection was treated successfully with amphotericin B. This case extends the clinical spectrum of zygomycosis associated with deferoxamine use.

\section{Gase report}

Divisions of Infectious Diseases and Geriatric Medicine, Medical School, Department of Veterans Affairs Medical Center, Ann Arbor, Michigan, USA.

Correspondence: Dr Carol A. Kauffman, Veterans Affairs Medical Center, 2215 Fuller Road, Ann Arbor, Michigan 48105 , USA.
A 71 -year-old man with myelodysplastic syndrome, coronary artery disease, and insulin requiring diabetes mellitus, was admitted to hospital in August 1992 for evaluation of pneumonia. $\mathrm{He}$ had been diagnosed with myelodysplasia by bone 
marrow biopsy 3 years earlier and required weekly transfusions since that time to maintain a haematocrit of $26-28 \%$. Twenty months prior to admission he was started on deferoxamine, 1 gram per day, for secondary iron overload. In August 1991, he developed several crusted nodules on his left forearm and abdomen. Biopsy yielded Blastomyces dermatitidis. Chest roentgenogram, bone scan, and cultures of other sites revealed no evidence of disseminated disease. He was treated with $400 \mathrm{mg}$ of ketoconazole daily. His lesions resolved within 3 months. Because of gastrointestinal intolerance, he was switched to fluconazole $400 \mathrm{mg}$ daily and it was planned to treat him for a total of 1 year. The transfusions and deferoxamine were continued throughout this time.

On admission in August 1992, he complained of a non-productive cough, fever, and chills. $\mathrm{He}$ denied fatigue, dyspnoea, haemoptysis, or pleuritic pain. His temperature was $37.8^{\circ} \mathrm{C}$, pulse 120 beats $\min ^{-1}$, blood pressure 146/56 mmHg. Rales were heard in the right apex, and the rest of the physical examination was within normal limits. The chest roentgenogram showed a right upper lobe infiltrate (Fig. 1). The white blood cell count was $5700 \mu^{-1}$ with $67 \%$ neutrophils, $29 \%$ lymphocytes, and $4 \%$ monocytes. Cefuroxime was begun for empiric therapy of pneumonia, but the patient remained febrile. Bronchoscopy with brushings and bronchoalveolar lavage, but no biopsy, was negative for mycobacteria, fungi, bacteria, and neoplastic cells. Fluconazole therapy was continued.

One month later the patient was re-admitted with progressive swelling, tenderness, and ery- thema of the right calf in the absence of a history of trauma to the site. He was febrile to $38.4{ }^{\circ} \mathrm{C}$ and had a warm, erythematous $8 \times 10 \mathrm{~cm}$ plaque on his right calf with edema distal to the lesion. The white blood cell count was $4100 \mu \mathrm{l}^{-1}$ with $65 \%$ neutrophils, $29 \%$ lymphocytes, $5 \%$ monocytes, and $1 \%$ myelocytes. Throughout the hospitalization, his serum glucose remained between $150 \mathrm{mg} \mathrm{dl}^{-1}$ and $250 \mathrm{mg} \mathrm{dl}^{-1}$. The chest radiograph showed no change in the right upper lobe infiltrate. Right lower extremity Doppler studies were negative for venous thrombosis. The patient was treated with intravenous ampicillin/sulbactam for presumed cellulitis without improvement. Punch biopsy of the lesion revealed no pathogens, and repeat bronchoscopy with bronchoalveolar lavage was also negative.

Eleven days later he developed worsening pain and swelling of the right calf. Foul smelling, purulent drainage was present at the site of the previous biopsy (Fig. 2). Cultures of the discharge grew coagulase negative staphylococci and group D enterococci. No improvement was noted with vancomycin and ampicillin/sulbactam. Five days later the patient developed 5 dime-sized, tender blueblack lesions on the plantar surface of the right foot and heel (Fig. 3). Ten ml of serosanguinous material was aspirated from the calf lesion and culture yielded Rhizopus species. Deferoxamine was discontinued, and intravenous amphotericin B was begun and continued for a total of $2 \mathrm{~g}$ with resolution of the lesions on the leg as well as the right upper lobe infiltrate over 6 weeks. The patient's course was complicated by Staphylococcus aureus bacteremia from an indwelling catheter
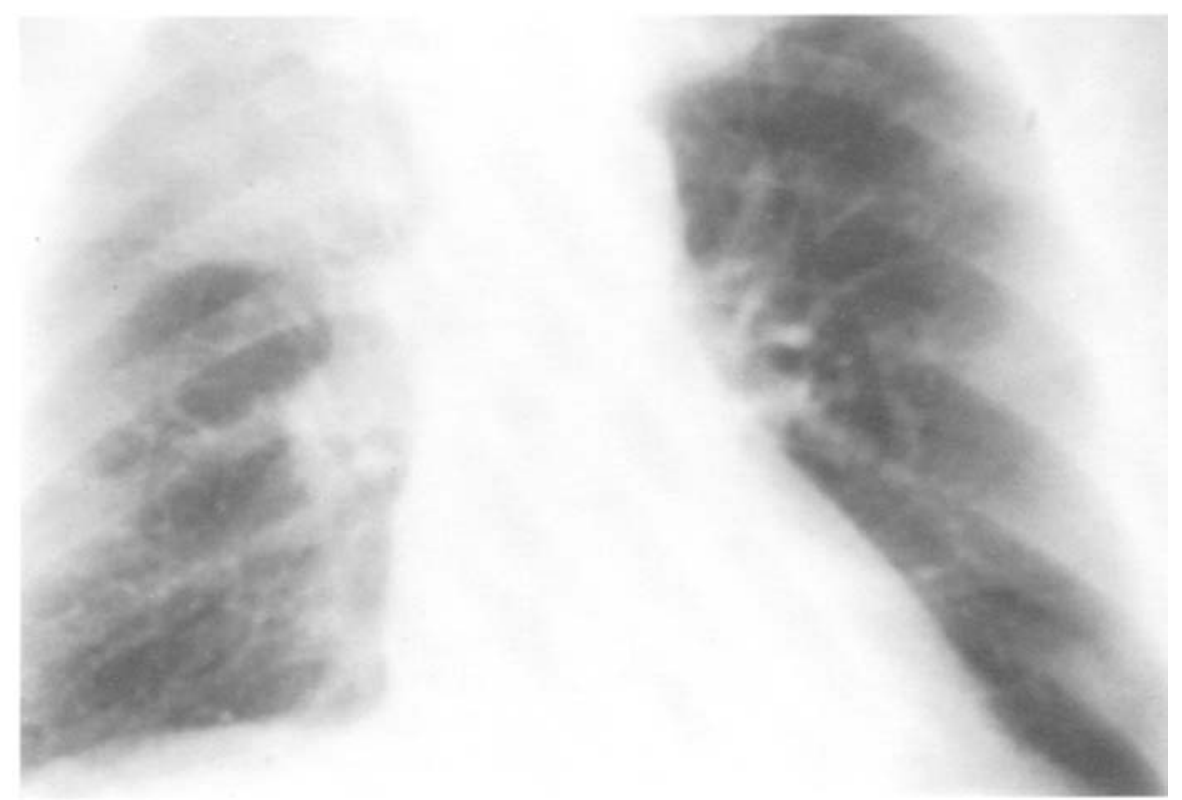

Figure 1. Chest roentgenogram showing a right upper lobe infiltrate. 


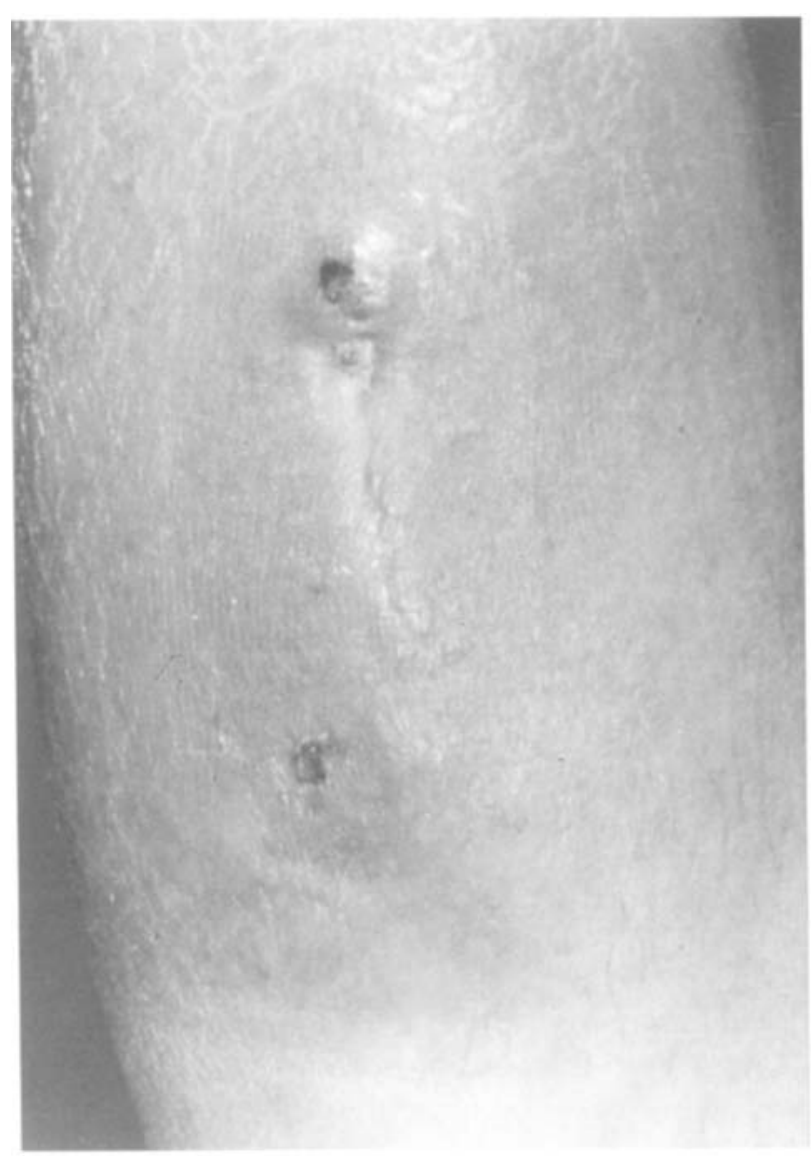

Figure 2. Cutaneous zygomycosis at the site of a previous biopsy of the right calf.

requiring treatment with anti-staphylococcal antibiotics and removal of the catheter and superinfection of the calf lesion with enterococci and Pseudomonas, for which he received oral ciprofloxacin.

Deferoxamine therapy was restarted 3 months after its discontinuance. Ten weeks after the deferoxamine therapy was re-started, the patient presented with sepsis and acute abdominal pain. Laparotomy revealed ischaemic colon, which was resected. Six weeks later, a splenectomy was performed for a splenic abscess. No fungi were seen or isolated during either operative procedure. He developed a splenic artery-duodenal fistula, had recurrent episodes of gram-negative bacterial sepsis and gastrointestinal bleeding, and finally succumbed 15 months after onset of the Rhizopus infection.

\section{Discussion}

Zygomycosis refers to infection with fungi of the order Mucorales, which includes, among others, the genera Rhizopus, Rhizomucor, Absidia, Mucor, and Cunninghamella. These organisms are ubiquitous,

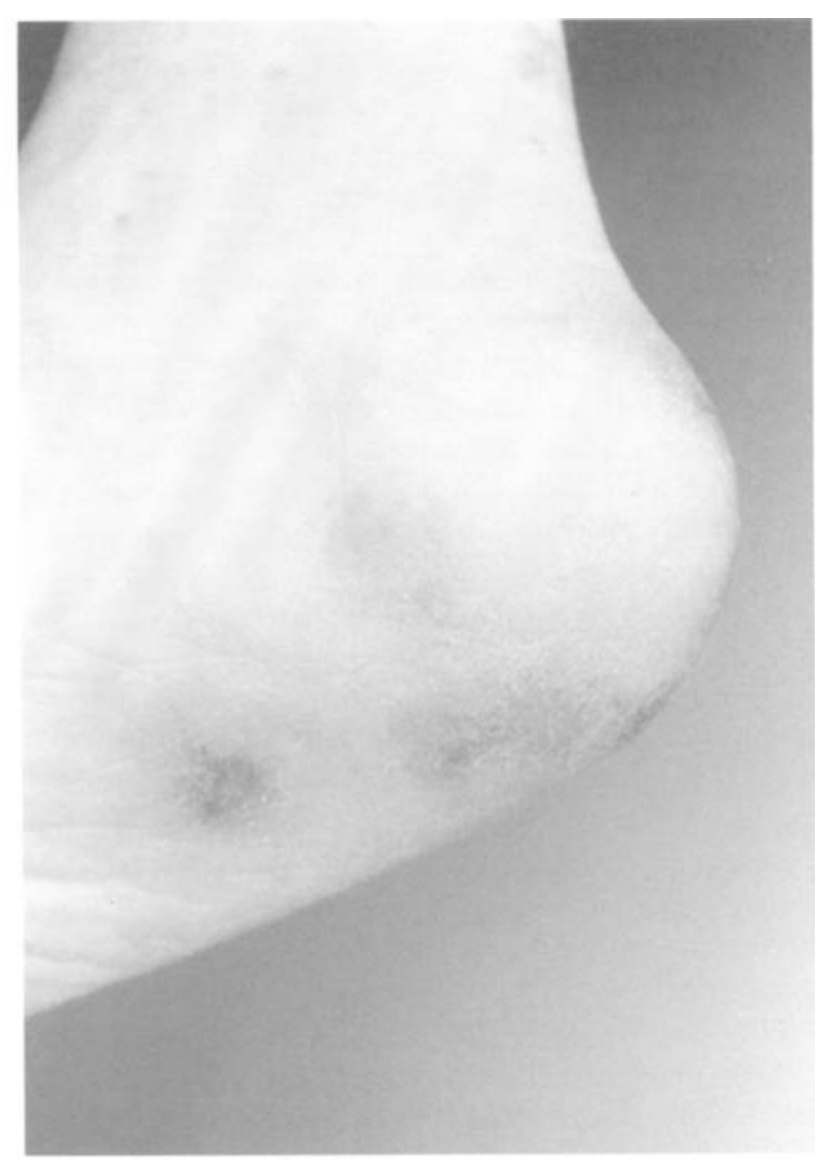

Figure 3. Cutaneous zygomycosis of the right foot and heel

found in abundance in soil, compost, and mouldy bread and fruit [13]. Despite the prevalence of these organisms and frequent exposure to them, an immunocompetent host effectively prevents their growth so that infection occurs only rarely. The most familiar examples of zygomycosis are rhinocerebral infection occurring in the setting of diabetic ketoacidosis $[1,2,13]$ and pulmonary or rhinocerebral infection in neutropenic patients [ 1 , $2,14]$. Additionally, gastrointestinal infection in patients with protein-calorie malnutrition or gastrointestinal ulceration [15], and embolic cerebrovascular disease in intravenous drug users have also been described [16].

Cutaneous zygomycosis takes several different forms. Some infections are fulminant with multiple cutaneous lesions noted during the course of haematogenously spread disseminated infection [14, 17]. When the organisms are inoculated directly into tissue in the course of severe trauma or burns, zygomycosis can present as relentlessly progressive localized cutaneous and subcutaneous infection requiring aggressive surgical management for survival [18]. A more indolent presentation of cutaneous zygomycosis has been noted at the sites of surgical wounds covered with Elastoplast dress- 
ings, which had been contaminated with Rhizopus, and around surgical drains covered with ostomy bags $[19,20]$. Still more chronic has been the presentation of isolated cutaneous zygomycosis in patients without preceding trauma or other underlying systemic illnesses [21].

In all of the reports of cutaneous involvement with the Mucorales, the hallmark has been tissue necrosis. The necrotic calf lesion and the subsequent development of multiple necrotic lesions at a distant site on the heel provided the first clues as to the true nature of our patient's infection. He most likely had involvement of the popliteal or posterior tibial artery with subsequent embolization to the smaller arteries of the calcaneal area. The infection in his leg evolved over 6 weeks. In the absence of a history of trauma or the presence of any cutaneous ulcerations at presentation, it appeared most likely that the calf lesion was the result of haematogenous spread from the lung. The chronicity of both the lung and calf lesions were surprising, however, especially in light of his treatment with deferoxamine.

Since the mid 1980s, a new association between zygomycosis and the administration of deferoxamine has received attention. Originally described in haemodialysis patients receiving chelation therapy for aluminum overload, the syndrome has now been documented in approximately 50 patients on haemodialysis and 15 patients with haematologic disorders who received deferoxamine for iron overload [3-12, 22]. Several explanations have been proposed for the increased susceptibility to zygomycosis in these patients, but it appears most likely that the fungi utilize the deferoxamine as a siderophore to capture iron essential for their growth. Several genera of Mucorales, including Rhizopus, have been shown to produce only small amounts of siderophores for their own use [23]. Human plasma and mucosal surfaces normally contain little free iron, most of it having been sequestered by the iron-binding proteins transferrin and lactoferrin [24]. Thus, deferoxamine can act as an exogenous siderophore for the Mucorales, enabling the fungi to efficiently capture iron in iron-poor environments [25-27].

The clinical course of our patient was less fulminant than that described for most patients on deferoxamine therapy. In previous reports of patients with zygomycosis associated with deferoxamine therapy, disseminated or rhinocerebral infection has been most common and the fatality rate has been $88 \%$ [3]. It has been suggested that the infection is more rapidly progressive in dialysis patients because of the prolonged half-life of deferoxamine and the iron-deferoxamine chelate in patients with renal failure [27]. On the other hand, infections in patients with haematologic conditions requiring deferoxamine have also had a fulminant course [3].

Indolent presentations of deferoxamineassociated zygomycosis are rare. Sands et al., described a patient with beta-thalassemia receiving deferoxamine who developed lymphadenopathy and cutaneous lesions which were due to Cunninghamella bertholletiae and which progressed slowly over 3 months [4]. The course in that patient was similar to that in our patient, and in both patients amphotericin B therapy was successful. We do not know why our patient's course was slowly progressive. It is tempting to speculate that chronic use of fluconazole for treatment of prior infection with $B$. dermatitidis may have suppressed growth of the organism, but there are no data in humans showing activity of the azoles against the Mucorales [13]. Generally, it is assumed the azoles have no role in the treatment of zygomycosis. It is also possible that the strain of Rhizopus causing infection was less virulent or less able to use the irondeferoxamine complex as a source of iron for growth [22].

Therapy of zygomycosis consists of aggressive surgical debridement, correction of any underlying risk factors, and amphotericin B. In those patients receiving deferoxamine, the drug must be stopped. Because of our patient's chronic course, his desire not to have extensive surgical debridement performed, and the absence of progression of the cutaneous and pulmonary lesions on amphotericin B, we treated him with antifungal therapy only. However, in most cases, surgical debridement is essential for resolution of the infection $[18,19]$.

\section{References}

1 Marchevsky, A. M., Bottone, E. J., Geller, S. A. \& Giger, D. K. (1980) The changing spectrum of disease, etiology, and diagnosis of mucormycosis. Human Pathol. 11, 457-464.

2 Parfrey, N. A. (1986) Improved diagnosis and prognosis of mucormycosis. Medicine (Baltimore) 65, 113-123.

3 Daly, A. L., Velazquez, L. A., Bradley, S. F. \& Kauffman, C. A. (1989) Mucormycosis: Association with deferoxamine therapy. Am. F. Med. 87, 468-471.

4 Sands, J. M., Macher, A. M., Ley, T. J. \& Nienhuis, A. W. (1985) Disseminated infection caused by Cunninghamella bertholletiae in a patient with betathalassemia. Ann. Intern. Med. 102, 59-63.

5 Boelaert, J. R., Fenves, A. Z. \& Coburn, J. W. (1991) Deferoxamine therapy and muycormycosis in dialysis patients: Report of an international registry. Am. F. Kidney Dis. 18, 660-667.

6 Eiser, A. R., Slifkin, R. F. \& Neff, M. S. (1987) Intestinal mucormycosis in hemodialysis patients following deferoxamine. Am. F. Kidney Dis. 10, 71-73.

7 Boelaert, J. R., van Roost, G. F., Vergauwe, P. L., 
Verbanck, J.J., de Vroey, C. \& Segaert, M. F. (1988) The role of desferrioxamine in dialysis-associated mucormycosis: report of three cases and review of the literature. Clin. Nephrol. 29, 261-266.

8 Sane, A., Manzi, S., Perfect, J., Herzberg, A. J. \& Moore, J. O. (1989) Deferoxamine treatment as a risk factor for zygomycete infection. 7. Infect. Dis. 159, 151-152.

9 Ingram, C. W., Sennesh, J., Cooper, J. N. \& Perfect, J. R. (1989) Disseminated zygomycosis: Report of four cases and review. Rev. Infect. Dis. 11, 741-754.

10 Rex, J. H., Ginsberg, A. M., Fries, L. F., Pass, H. I. \& Kwon-Chung, K. J. (1988) Cunninghamella bertholletiae infection associated with deferoxamine therapy. Rev. Infect. Dis. 10, $1187-1194$.

1) Windus, D. W., Stokes, T. J., Julian, B. A. \& Fenves, A. Z. (1987) Fatal Rhizopus infections in hemodialysis patients receiving deferoxamine. Ann. Intern. Med. 107, 678-680.

12. Brennan, R. O., Crain, B. J., Proctor, A. M. \& Durack, D. T. (1983) Canninghamella: A newly recognized cause of rhinocerebral mucormycosis. Am. J. Clin. Pathol. 80, $98-102$.

13 Sugar, A. M. (1992) Mucormycosis. Clin. Infect. Dis. 14 (suppl. 1), S126-S129.

14 Meyer, R. D., Rosen, P. \& Armstrong, D. (1972) Phycomycosis complicating leukemia and lymphoma. Ann. Intern. Med. 77, $871-879$

15 Lyon, D. T., Schubert, T. T., Mantia, A. G. \& Kaplan, M. H. (1979) Phycomycosis of the gastrointestinal tract. Am. 7. Gastroenterol. 72, 379 394.

16 Stave, G. M., Heimberger, T. \& Kerkering, T. M. (1989) Zygomycosis of the basal ganglia in intravenous drug users. Am. 7. Med. 86, 115-117.

17 Meyer, R. D., Kaplan, M. H., Ong, M. \& Armstrong, D.
(1973) Cutaneous lesions in disseminated mucormycosis. fAMA 225, 737-738.

18 Vainrub, B., Macareno, A., Mandel, S. \& Musher, D. M. (1988) Wound zygomycosis (mucormycosis) in otherwise healthy adults. Am. F. Med. 84, 546-548.

19 Paparello, S. F., Parry, R. L., MacGillivray, D. C., Brock, N. \& Mayers, D. L. (1992) Hospital-acquired wound mucormycosis. Clin. Infect. Dis. 14, 350-352.

20 Gartenberg, G., Bottone, E. J., Keusch, G. T. \& Weitzman, I. (1978) Hospital-acquired mucormycosis (Rhizopus rhizopodiformis) of skin and subcutaneous tissue. Epidemiology, mycology, and treatment. $\mathcal{N}$. Engl. F. Med. 299, 1115-1118.

21 Geller, J. D., Peters, M. S. \& Su, W. P. D. (1993) Cutaneous mucormycosis resembling superficial granulomatous pyoderma in an immunocompetent host. 7 . Am. Acad. Dermatol. 29, 462-465.

22 Boelaert, J. R., de Locht, M. \& Schneider, Y-J. (1994) The effect of deferoxamine on different zygomycetes. 7. Infect. Dis. 169, 231 232.

23 Holzberg, M. \& Artis, W. M. (1983) Hydroxamate siderophore production by opportunistic and systemic fungal pathogens. Infect. Immun. 40, 1134-1139.

24 Weinberg, E. D. (1978) Iron and infections. Microbiol. Rev. 42, 45-66.

25 van Cutsem, J. \& Boelaert, J. R. (1989) Effects of deferoxamine, feroxamine, and iron on experimental mucormycosis (zygomycosis). Kidney Int. 36, 1061-1068.

26 Verdonck, A. K., Boelaert, J. R., Gordts, B. Z. \& Van Landuyt, H. W. (1993) Effect of ferrioxamine on the growth of Rhizopus. Mycoses 36, 9-12.

27 Boelaert, J. R., de Locht, M., van Cutsem, J. et al. (1993) Mucormycosis during deferoxamine therapy is a siderophore-mediated infection. In vitro and in vivo animal studies. 7. Clin. Invest. 91, 1979-1986. 